\title{
Como Relações Públicas pode contribuir para 0 desenvolvimento de instituições do Terceiro Setor
}

\author{
The public relations and his contribution to the developement \\ of third sector's institutions
}

\author{
Cleuza GeRTRudes Gimenes Cesca \\ Profa. da Pontifícia Universidade Católica de Campinas.
}

\begin{abstract}
Resumo
Visando propor que o Terceiro Setor utilize relações públicas para fazer a comunicação com seus diversos públicos, fez-se estudo de casos de quatro instituições que representam segmentos diferentes desse setor na cidade de Campinas/SP e os dados obtidos mostraram que essas instituições não possuem setores nem assessorias externas de relações públicas, embora executem algumas atividades que podem ser consideradas dessa área, pois a presença de voluntários com boa vontade e bem intencionados é que tem feito, na maioria dos casos, essas instituições caminharem, mas devagar, sendo que reconhecem elas que um trabalho planejado de relações públicas seria muito importante para o desenvolvimento da comunicação com os seus públicos.

Palavras-chave: Relações Públicas, Terceiro Setor, Pesquisa.
\end{abstract}

Introdução

A área social trouxe demandas que o Estado não tem conseguido atender. Diante disso, a sociedade procura oferecer a sua contribuição visando suprir essa lacuna e, assim, minimizar as dificuldades dos menos favorecidos; surgem as organizações do chamado terceiro setor, com várias denominações e um objetivo comum: possibilitar ações sociais que venham transformar a realidade do público em prol do qual se propuserem a trabalhar.

O terceiro setor compreende as instituições que realizam práticas sociais, sem fins lucrativos, que geram bens e serviços de caráter público, tais como: instituições religiosas, clubes de serviços, entidades beneficentes, centros sociais, organizações de voluntariado, Ongs etc.

A constituição de uma sociedade compreende três setores:
O Primeiro Setor, (Estadopoder) poder público: recebe apoio financeiro público para fins públicos.

O Segundo Setor, (Mercadolucro) empreendimentos econômicos: recebe apoio financeiro privado para fins privados.

O Terceiro Setor, (sociedadedeveres) empresas sociais: recebe apoio financeiro privado e público para fins públicos.

Visa também o Terceiro Setor, trabalhar valores com seus públicos de interesse, que os motivem a busca de qualidade de vida, o despertar para a cidadania, a partilha, a solidariedade, a fé, o profissionalismo das habilidades etc.

Por aglutinarem grande número de voluntários, das mais variadas formações, criaram uma forma de administrar, própria. Essa atitude tem trazido dificuldades para a gestão, limitando suas ações, pois o crescimento requer pessoal especializado e profissionalismo. 
Cientes dessa constatação, algumas instituições de porte maior já mantêm em seus quadros esses profissionais, com vínculo empregatício, tornando-se, portanto, também, geradoras de empregos. Nesse contexto estão também as relações públicas, que são uma atividade que busca manter as boas relações entre as organizações e seus públicos, usando para isso as estratégias adequadas que são do domínio dessa área da comunicação social, que são:

- Assessoria e consultoria.

- Pesquisa

- Planejamento

- Execução: elabora e distribui noticiário por meio de press release para os veículos de comunicação social; organiza e dirige entrevistas coletivas; mantém contatos permanentes com a imprensa; supervisiona coberturas fotográficas e de TV, orientando a realização do trabalho; organiza e mantém atualizados arquivos de imprensa, fotografias, filmes etc.; elabora publicações da instituição para funcionários, clientes, fornecedores etc.; folhetos, relatórios, livros, cartazes etc.; campanhas publicitárias; promoções institucionais; quadros de avisos, exposições, mostras etc.; organiza e dirige visitas às instalações, viagens etc.; redige discursos, mensagens, correspondências etc.; cria e dirige sistemas de comunicação específicos; elabora materiais audiovisuais; mantém contatos pessoais por outros meios com líderes de opinião, empresários, autoridades etc.; atende consultas, pedidos etc.; organiza entrevistas e contatos com a direção da instituição; organiza promoções e eventos, tais como: inaugurações, comemorações, convenções, congressos, conferências, simpósios etc.; dirige cerimonial; representa a instituição e sua direção; mantém cadastro de líderes de opinião de interesse da instituição.

- avaliação:

Avalia, com técnicas de pesquisa e análise, os resultados dos trabalhos desenvolvidos.

Visa, portanto, este trabalho, dar uma contribuição para que essas instituições sintam a força da comunicação, por meio das estratégias de relações públicas, para a sua viabilização como terceiro setor eficiente e forte.

A Realidade da atuação de Relações Públicas num recorte feito em Instituições do Terceiro Setor localizadas na Cidade de Campinas - SP

As Instituições do $3^{\circ}$ Setor que foram pesquisadas

\section{Instituição Filantrópica}

Essa instituição é mantida pela sociedade Feminina de Assistência à Infância, presta serviços à comunidade de Campinas desde 1914, desenvolvendo Programa Sócio-Educativo em meio aberto, para crianças de dois a onze anos de idade, enquanto seus pais ou responsáveis trabalham fora do lar para manutenção ou sustento da família.

Fundada pelo Bispo da Arquidiocese de Campinas, Dom Nery, essa instituição tem como objetivo o pioneirismo de ações e o desenvolvimento de projetos sócio educativos.

Em 1997 foi inaugurada a Unidade II. Juntas atendem 350 crianças e têm outras 1.100 na lista de espera. Tem 35 funcionários com vínculo empregatício, 100 voluntários e 60 sócios.

A instituição não possui setor de 
relações públicas/comunicação, apenas tem uma assessoria de imprensa prestada por uma jornalista voluntária. É mantida pelo poder público (verba educacional) assistências sociais, Conselho da Criança, doações de sócios. Empresas da região fazem ações de responsabilidade social em numerário, esporadicamente.

A instituição utiliza como veículos de comunicação: folhetos, manual, quadro de avisos, vídeo, jornal interno. Os seguintes eventos também são realizados: café da manhã, feijoada.

A partir da definição do que são relações públicas e questionada se RP seria útil na instituição, nossa entrevistada respondeu que seria muito útil.

\section{Instituição de Voluntariado}

Fundada em 22/05/1948, funciona em duas salas na região central da cidade de Campinas. São 15 mulheres que se dedicam a confeccionar enxovais para crianças recém-nascidas e cobertores e roupas para crianças de até 12 anos. Duas vezes por ano, inverno e verão, elas distribuem a produção de seis mil peças anuais para hospitais e maternidades.

É mantida, portanto, por associados e a captação de recursos é feita por meio de eventos, como: feijoada em parceria com restaurante da cidade e desfiles beneficentes. As parcerias são buscadas pelas senhoras voluntárias que pertencem a famílias tradicionais de Campinas; uma história que vem de mãe para filha.

Não possui logomarca, papelaria padronizada, identificação de fachada, site, boletim, quadro de avisos, nem mesmo um endereço eletrônico, nada que a identifique formalmente.
A partir da definição do que são relações públicas e questionada se Relações Públicas seria útil na instituição, nossa entrevistada disse que seria muito importante a instituição poder contar com um serviço especializado.

\section{Instituição Religiosa}

Em 1944, os padres salvatorianos vieram lecionar no seminário local em Campinas e em 1945, D. Paulo de Tarso Campos deu início à construção do templo da paróquia, confiada à Congregação dos Salvatorianos. A fundação da Paróquia ocorreu em 11 de fevereiro de 1961. Em 1996, com a saída dos Salvatorianos, a Paróquia foi assumida pelos padres diocesanos de Campinas. Para a sua melhor administração, atualmente a Paróquia conta com um Conselho de Pastoral Paroquial (CPP) e outro Econômico Administrativo (CAE). Nela é desenvolvido um trabalho de evangelização organizado por grupos de diversas pastorais, bem como são realizados serviços sociais de atendimento e acolhimento à comunidade. E como está situada em um ponto estratégico da cidade de Campinas, ou seja, de fácil acesso à sociedade, a paróquia tem uma vocação e missão urbanas muito bem definidas.

\section{Os serviços oferecidos}

Estão organizados em três diferentes dimensões: sacramental, catequético-permanente e comunitária.

\section{Dimensão Sacramental}

Compreende: Pastoral do Batismo; Pastoral do Casamento; Pastoral dos Noivos; Pré-catequese, Catequese e Perseverança; 
Iniciação Cristã de Adultos (ICA) e Caminhada de Emaús.

Dimensão Comunitária

Compreende: Conselho de Pastoral Paroquial (CPP); Conselho Administrativo $e$ Econômico (CAE); Formação; Campanha da Fraternidade; Pastoral do Dízimo; Evento; Liturgia; Pastoral da Comunicação (PasCom).

Dimensão Catequético-Permanente

Compreende: Casais; Comunidade Efeta; Comunidade El Chaddai - Pantokrator; Divinos Jovens; Pastoral Familiar; Vida Ascendente; Mater Ecclesiae; Missão Urbana; Pastoral da Saúde; Vicentino; Promoção Humana.

A paróquia tem sete funcionários com vínculo empregatício, cerca de 100 voluntários com freqüência semanal. A formação desses voluntários é a mais variada possível, mas esses fazem cursos para irem se adequando as necessidades da paróquia. Não possui setor de relações públicas, mas há uma assessoria de imprensa voluntária, também responsável pelo site. A paróquia é mantida pelo dízimo, coleta das missas, doações esporádicas.

Não há empresas privadas que fazem ações de responsabilidade na paróquia. A divulgação de suas atividades é feita por meio de um boletim semestral, revista anual e site.

A paróquia trabalha com os seguintes veículos de comunicação: ofício, circular, quadro de avisos, mural cartaz/banner, telegrama, email, jornal, site, folder, panfleto, revista.

Há como registro o livro tombo, documentos oficiais, fotos e vídeos recentes. Realiza eventos como: confraternizações, almoços, chás, festa junina, comemorações da páscoa, natal.

A paróquia não busca parcerias privadas para viabilizar suas atividades.

Para o nosso entrevistado as instituições religiosas sempre desenvolveram ações de responsabilidade social no Brasil. Essa denominação é recente, mas as suas atividades fazem parte dos propósitos da Igreja católica. Para ele a paróquia não é uma geradora de emprego.

A partir da definição do que são relações públicas e questionado se Relações Públicas seria útil na paróquia, nosso entrevistado respondeu que seria muito útil.

\section{Clube de Serviços}

Presta serviços à comunidade local e mundial, sem fins lucrativos, não é secreto, nem fillantrópico ou social. É uma associação de líderes de negócios e profissionais, unidos no mundo inteiro, que prestam serviço humanitário, fomentam um elevado padrão de ética em todas as profissões e ajudam a estabelecer a paz e a boa vontade no mundo. É a primeira associação de prestação de clubes de serviço no mundo. $\mathrm{O}$ primeiro foi fundado em Chicago, Illinois, nos Estados Unidos, em 23 de fevereiro de 1905, por Paul Harris. Possui registro de Utilidade Pública Federal. O "staff" é composto por: 1 presidente, 16 diretores, governadores e clubes.

$\mathrm{Na}$ cidade de Campinas são 12 clubes. Não há funcionário com vínculo empregatício, são todos voluntários, com freqüência semanal.

O clube é mantido com a contribuição dos associados, e não há empresas privadas que nele 
desenvolvem ações de responsabilidade social.

Utilizam os veículos: carta, ofício, "folder" para as suas comunicações. Há registros de sua trajetória em forma de fotos e videos. Participam de campanhas de vacinação e eventos com os patrulheiros da cidade.

A partir da definição do que são relações públicas e questionado se relações públicas seria útil na instituição, nosso entrevistado afirmou que seria muito útil poderem contar com esse trabalho, principalmente para assessoria de imprensa.

\section{Análise dos dados obtidos}

\section{- instituição religiosa católica}

As instituições religiosas católicas são reconhecidamente muito atuantes como instituições do Terceiro Setor, há muitos anos. A Paróquia é um grande exemplo a ser seguido. Desenvolve um trabalho inegavelmente de grande valor junto a todos os seus públicos.

Todas as suas ações estão organizadas em três diferentes dimensões: sacramental, catequético -permanente e comunitária. É uma dinâmica que flui de maneira organizada e precisa, sob a eficiente coordenação geral de seu Pároco, Pe. José Arlindo De Nadai.

A Pastoral da Comunicação faz a comunicação formal com os públicos da Paróquia por meio de site, boletim e revista. A produção é feita por voluntários, tendo entre eles especialistas em comunicação. Todas as demais pastorais, no que tange a relações públicas/comunicação, não contam com pessoas especializadas.

Em todas as ações que se realiza nota-se atividades próprias de relações públicas, embora se perceba a falta da aplicação de técnicas apropriadas e atitudes pró-ativas.

- instituição filantrópica

Possui uma assessoria de imprensa voluntária, a única especialista. As outras atividade de comunicação são produzidas por pessoas voluntárias ou com vínculo empregatício, sem formação específica.

- clube de serviço

Possui algumas atividades de comunicação executadas pelos rotarianos, pessoas competentes em seus campos de ação, mas desconhecedores das técnicas especializadas para fazer comunicação. Os veículos vindos de suas instâncias superiores, como a revista, são adequados.

- instituição de voluntariado

Não possui praticamente nada que possa ser considerado atividade de relações públicas. Apenas dois eventos, em parceria, divulgam o trabalho de 15 abnegadas senhoras.

\section{Resultado da Pesquisa}

Nenhuma das instituições do Terceiro Setor que foram pesquisadas possui setor/assessoria de relações públicas. Observou-se, porém, que algumas das atividades realizadas podem ser consideradas de relações públicas, mas requerem planejamento para não se tornarem ações isoladas e com isso perderem a sua força.

A presença de pessoal especializado em relações públicas/ comunicação é pequena. Muitos que atuam nessas instituições são voluntários que trazem a sua contribuição dentro da sua área de formação. Quando a sua área de 
formação não tem aplicação, a dedicação e a boa vontade são aproveitadas da melhor forma possível.

Todas as instituições reconhecem a grande importância do trabalho de relações públicas para o desenvolvimento do Terceiro Setor.

Os estudos feitos e pesquisas realizadas junto a essas quatro instituições de segmentos diferentes do Terceiro Setor permitem que se faça as seguintes afirmações:

$\square$ o terceiro setor é grande e está em crescimento na cidade de Campinas- SP;

$\square$ as pessoas que atuam no Terceiro Setor não são só voluntárias;

$\square$ o terceiro setor contribui para a geração de empregos;

$\square$ o terceiro setor não conta com serviços de relações públicas;

$\square$ relações públicas é uma atividade que pode contribuir de maneira significativa para o desenvolvimento e fortalecimento do Terceiro Setor, utilizando técnicas apropriadas em todas as ações das instituições, inclusive sendo pró-ativa.

$\begin{array}{lrrr}\text { PROPOSTA } & \text { DE } & \text { PROJETO } & \text { DE } \\ \text { RELAÇÕES PÚBLICAS } & \text { PARA } & \text { AS } \\ \text { INSTITUIÇÕES DO DO TERCEIRO } & \text { DO } \\ \text { SETOR QUE FORAM PESQUISADAS }\end{array}$

\section{Objetivos}

$\square$ Objetivo Geral: Fortalecer o conceito/imagem da instituição perante os seus públicos.

$\square$ Objetivos Específicos:

Divulgar a instituição

Aproximar os públicos

Efetivar a relação instituição/ públicos.

\section{Públicos:}

${ }^{1}$ Essas estratégias deverão ser colocadas em um cronograma e para cada uma delas, deverá ser elaborado um planejamento específico. $\square$ Interno-vinculado: funcionários

$\square$ Interno-desvinculado:

voluntários, pessoas que prestam serviços dentro da instituição.

$\square$ Misto-vinculado: funcionário que prestam serviço fora da instituição.

$\square$ Misto-desvinculado: fornecedores e distribuidores.

$\square$ Externo: comunidade, imprensa, órgãos governamentais etc.

Estratégias (foram definidas algumas para cada uma das instituições que foram pesquisadas). ${ }^{1}$

\section{Instituição de voluntariado}

$\square$ Realização de Pesquisa institucional

$\square$ Criação de um logotipo

$\square$ Criação de um vídeo institucional

$\square$ Produção de folder institucional

$\square$ Identificação de fachada

$\square$ Produção de placas de identificação

$\square$ Realização de eventos para captação de recursos

$\square$ Criação de quadro de avisos interno

$\square$ Produção de livro comemorativo

$\square$ Realização de Campanha para ampliação do número de sócios

$\square$ Criação de um boletim informativo para sócios

$\square$ Criação de site e e-mail

$\square$ Realização de clipagem

$\square$ Registro de todos os acontecimentos da instituição (fotos/ filmagem)

$\square$ Ampliação e organização do espaço físico

$\square$ Realização de parcerias com outras instituições do terceiro setor

$\square$ Realização de assessoria de imprensa.

$\square$ Produção de cartões de natal em parceria com escolas de artes

$\square$ Padronização de papelaria $\square$ Padronização da comunicação escrita (impressa e eletrônica)

$\square$ Realização de Bazar Beneficente para a venda de enxovais/peças produzidas pela oficina, gerando receita.

$\square$ Produção de um relatório social 


\section{Instituição beneficente}

$\square$ Realização de Pesquisa institucional

$\square$ Produção de um Livro comemorativo

$\square$ Produção de vídeo institucional

$\square$ Criação de Boletim mensal

$\square$ Criação de folder institucional

$\square$ Realização de Clipagem

$\square$ Criação de site institucional

$\square$ Realização de eventos para a comunidade (festa junina, festa das nações) visando gerar renda

$\square$ Realização de Confraternização com voluntários

$\square$ Realização de Confraternização com funcionários

$\square$ Produção de calendário para brindes, com ilustrações das crianças

$\square$ Produção de cartões de natal com desenhos das crianças da creche

$\square$ Padronização da papelaria

$\square$ Padronização da comunicação escrita - impressa e eletrônica.

$\square$ Comemorações de datas significativas para a creche: dia das crianças, mães, pais, páscoa, natal, aniversário da creche, aniversário do fundador.

$\square$ Realização de Assessoria de imprensa.

$\square$ Divulgação de tudo que a creche realiza.

$\square$ Publicação de artigos de sócios, diretoria, em datas oportunas.

$\square$ Realização de captação de recursos.

$\square$ Produção de um relatório social

$\square$ Produção de um Livro comemorativo.

\section{Instituição Religiosa:}

$\square$ Realização de Pesquisa institucional.

$\square$ Padronização da fachada da Paróquia.

$\square$ Produção de folder institucional $\square$ Produção de vídeo institucional

$\square$ Realização de cursos para as comunidades assistidas, visando gerar auto-sustento

$\square$ Realização de cursos para paroquianos e comunidade do entorno, visando gerar receita.

$\square$ Realização de excursões para paroquianos (peças teatrais, locais religiosos, exposições, cidades turísticas etc.).

$\square$ Disponibilização de espaço físico para festas de casamento, outras bodas, exposições, lançamentos, visando gerar receita.

$\square$ Atualização permanente do site

$\square$ Padronização da comunicação escrita - impressa e eletrônica.

$\square$ Realização de Assessoria de imprensa

$\square$ Realização de clipagem

$\square$ Produção de artigos pelos paroquianos para veiculação nos jornais da cidade

$\square$ Realização de entrevistas com o pároco e/ou paroquianos nas tvs locais

$\square$ Produção de Calendário de mesa para brinde

$\square$ Realização de campanha: "adote um estudante carente", junto aos paroquianos.

$\square$ Realização de reuniões do setor de relações públicas com a presença de representantes das pastorais.

$\square$ Realização de parcerias com o setor privado para viabilização das atividades das pastorais.

$\square$ Apoio especializado, técnico e logístico a todas as ações das pastorais.

$\square$ Produção de um livro comemorativo

$\square$ Produção de um relatório social anual.

\section{Clube de Serviço}

Realização de Pesquisa institucional

$\square$ Padronização da comunicação escrita - impressa e eletrônica.

$\square$ Assessoria de imprensa

$\square$ Divulgação das ações,

$\square$ Publicação de artigos de sócios em datas oportunas.

$\square$ Produção de Jornal mural e/ou Quadro de avisos

$\square$ Realização de Clipagem 
$\square$ Realização de Apoio a instituições

$\square$ Produção de Boletim mensal para os sócios

$\square$ Criação de folder institucional

$\square$ Produção de Livro comemorativo

$\square$ Realização de Confraternização entre os membros

$\square$ Realização de Confraternização entre os Rotary da cidade

$\square$ Criação de um site individualizado

$\square$ Realização de concursos culturais com a comunidade

$\square$ Realização de eventos para a comunidade: festa das nações, junina .

$\square$ Produção de Relatório social anual

\section{Recursos:}

Humanos: relacionar todos os necessários.

$\square$ Materiais: relacionar todos os necessários

$\square$ Físicos: relacionar todos os necessários.

Implantação

Descrição passo a passo de todo desenvolvimento do projeto.

\section{Fatores Condicionantes}

$\square$ Aprovação do projeto pela instituição

$\square$ Interesse do público ao qual é dirigido.

\section{Acompanhamento e Controle}

Serão feitos pelos organizadores por meio de cronograma de trabalho, observações, anotações e, se necessário, pesquisa.

\section{Avaliação}

Será feita pelos organizadores com base nos dados do acompanhamento e controle, repercussão na mídia, se for o caso, com a produção de um relatório final que será encaminhado à instância superior.

\section{Orçamento Previsto}

Relacionar conforme segue:

Recursos Materiais:

Recursos Humanos:

\begin{tabular}{|l|l|l|l|}
\hline Quantidade & ii ina a a & a ta & \\
\hline & & & \\
\hline & & & \\
\hline
\end{tabular}

Recursos Físicos:

\section{Conclusão}

O Terceiro Setor é amplo, composto por instituições com especificidades próprias. As instituições pesquisadas - religiosa, beneficente, voluntariado e clube de serviço - deixaram claro que um serviço de relações públicas muito facilitaria e contribuiria para a efetivação da relação instituição/ públicos.

Nem toda instituição pode, por determinação de seus estatutos, ter funcionários com vínculo empregatício ou voluntários. Mas aquelas cujos estatutos permitem, tornam-se geradoras de empregos e/ou abrem 
suas portas ao voluntariado. Tornamse, portanto, um nicho de mercado para varias profissões, em particular para relações públicas.

Pôde-se observar que as pesquisadas poderiam utilizar estratégias muito além daquelas que são postas em prática se um serviço de relações públicas, voluntário ou com vínculo empregatício, fizesse parte do quadro funcional dessas instituições.

O terceiro setor tem se sustentado com a disponibilidade do voluntariado, mas à medida que cresce começa a exigir também pessoas especializadas para atuarem nos seus diversos setores.

Pretende-se, a partir deste trabalho, contribuir efetivamente para com essas instituições, prestando assessoria de relações públicas voluntária.

\section{Recomendações}

Seria de grande valia que os alunos da Faculdade de Relações Públicas da PUC-Campinas fossem estimulados a participar de forma voluntária ou empregatícia de instituições do Terceiro Setor, exercitando os seus conhecimentos e contribuindo para o crescimento desse Setor que tem suprido as deficiências do Estado.

As disciplinas Consultoria e Responsabilidade Social que fazem parte do currículo de faculdade poderiam ser as catalisadoras dessa atividade.

\section{Resumen}

Con la intención de proponer que el tercer sector pueda utilizar relaciones publicas para hacer la comunicación con sus diversos públicos, hicimos un estudio de caso de cuatro instituciones que representan diferentes seguimientos de esto sector en la ciudad de Campinas/SP u los dados obttenidos enseñan que esas instituciones no poseen sectroes y accesorias externas de relaciones publicas, sin embargo, ejecutan algunas actividades que puedan ser consideradas de esta área, pues la presencia de voluntarios con buena voluntad y intenciones, es que tiene hecho la mayoría de los casos, esas instituciones caminan, pero muy despacio, siendo que reconocen que un trabajo planificado de relaciones publicas, sería muy importante para el desarrollo e la comunicación con sus públicos.

Palabras-clave: relaciones publicas, tercer sector, pesquisa.

\section{Referências}

ANDRADE, C. Teobaldo S. Curso de Relações Públicas. $5^{a}$ Ed. São Paulo: Summus, 1994.

BIVINS, Thomas. Handbook for Public Relations Writing. Illinois-USA: NTC, 1995

CESCA, Cleuza G. Gimenes. Comunicação Dirigida Escrita na Empresa - Teoria e prática. 4. edição - revisada, ampliada. São Paulo: Summus Editorial, 2006.

Organização de Eventos. 8. ed. São Paulo: Summus Editorial, 1997.

Cesca, Wilson. Estratégias

Empresariais Diante do Novo Consumidor. São Paulo: Summus Editorial, 2000.

CAPRIOTTI, Paul. Planificación Estratégica de la Imagen Corporativa. Barcelona: Ariel Comunicación, 1999.

CERTO, Samuel C. e J. Paul Peter. Administração Estratégica. Tradução Flávio Deni Steffen. São Paulo: Makron Books, 1993.

CHAPELL, R. T. \& W. L. Read. Comunicação Interna na Empresa Moderna. Tradução Edmond Jorge. Rio de Janeiro: Fórum, 1997.

CORRADO, Frank M. A Força da Comunicação. São Paulo: Makron Books, 1994.

DOTY, Doroty I. Publicity and Public Relations. New York: Barron's, 1990

ESTEVES, Sérgio A. P. (org).O Dragão e a Borboleta: sustentabilidade e responsabilidade social nos negócios. São Paulo: Axi Mundi-AMCE, 2000.

FINTAN, Lawless. A Responsabilidade Social das 
Empresas Multinacionais no $3^{\circ}$ setor. Tese. Depto filosofia da Puc-Rio de Janeiro, 1993.

FORTES, Waldyr Gutierrez. Relações Públicas: processo, funções, tecnologias e estratégias: Ed. UEL, 2004.

Transmarketing-estratégias avançadas de relações públicas no campo do marketing. São Paulo: Summus, 1999.

HARRIS, Thomas L. The Marketer's guide to Public Relations. New York: John Wiley \& Sons, 1991.

JORNAL Correio Popular. Caderno Projeto Cidadão. pg. 12- 24/08/2005.

KUNSCH, Margarida M. K. Planejamento de Relações Públicas na Comunicação Integrada. 4. ed. revisada e ampliada. São Paulo: Summus Editorial, 2003.

- Reações. Públicas e Modernidade - novos paradigmas na comunicação organizacional. São Paulo: Summus, 1997.

LAMPREIA, J. Martins. Comunicação Empresarial. Lisboa: Texto, 1992.

LLOYD, Herbert e Peter. Relações Públicas: as técnicas de comunicação no desenvolvimento das empresas. Lisboa: Presença, 1985.

Ed.Pirámide, 1990.

Relaciones Publicas. Madris:

MARTINELLI, Antônio C. $3^{\circ}$ Setor: Desenvolvimento Social Sustentado. Editora Paz e Terra. Rio de Janeiro, 1997.

OLIVER, Richard W. Como Serão as Coisas no Futuro. São Paulo: Negócio Editora, 1999.
OLIVEIRA, Maria José da Costa. A relação do Estado, da Sociedade e do Mercado na Construção da Cidadania. O Papel das Relações Públicas. Tese de doutorado, ECA/USP, 2001.

REGO, Francisco Gaudêncio Torquato. Comunicação Empresarial - Comunicação Institucional. São Paulo: Summus, 2004.

REVISTA "O Caminho". Ano 7-n²8-Ano 2006 -Edição Especial da Paróquia Divino Salvador de Campinas - São Paulo/SP.

REVISTA Brasil Rotário. Ano 80 D - n 997 julho/2005 do Rotary Club.

SCHERER-WARREN, I. Cidadania sem Fronteiras: ações coletivas na era da globalização. São Paulo: Hucitec, 1999.

TENÓRI0, Fernando G. (Org) Gestão de ONGs. $7^{a}$ Edição. São Paulo: Ed. Fundação Getúlio, 2003.

TOFFLER, A \& H. Criando uma Nova Civilização:a política da terceira onda. $5^{\mathrm{a}} \mathrm{Ed}$. Rio de Janeiro: Record, 1997.

Revista "0 Caminho" Jornal Correio Popular

\section{Meios eletrônicos}

www.terceirosetor.org.br www.fundaçãoabrinq.org.br www.ibase.org.br www.ethos.org.br www.parceirosvoluntários.org.br www.lexeditora.org.br www.benet.psi.br/rotary
Data do recebimento: 08/04/2008

Data do aceite: 20/05/2008 